\title{
Methodological issues in estimating sodium intake in the Korea National Health and Nutrition Examination Survey
}

\author{
Hyun Ja Kim, Kyungwon Oh \\ Division of Health and Nutrition Survey, Korea Centers for Disease Control and Prevention, Cheongju, Korea
}

\begin{abstract}
For policy goal setting, efficacy evaluations, and the development of related programs for reducing sodium intake, it is essential to accurately identify the amount of sodium intake in South Korea and constantly monitor its trends. The present study aimed to identify the status of sodium intake in South Korea and to review the methods and their validity for estimating sodium intake in each country; through this, we aim to determine more accurate methods for determining sodium intake and to monitor the trend in sodium intake for Korean citizens in the future. Using 24-hour dietary recall data from the 2012 Korea National Health and Nutrition Examination Survey (KNHANES) to estimate daily sodium intake, the average daily sodium intake among Koreans was 4,546 mg (men, 5,212 mg; women, 3,868 mg). In addition to the nutrition survey that uses the 24-hour dietary recall method, sodium intake can also be calculated from the amount of sodium excreted in 24-hour urine, 8-hour overnight urine, and spot urine samples. Although KNHANES uses the 24-hour dietary recall method to estimate the sodium intake, the 24-hour dietary recall method has the disadvantage of not being able to accurately determine the amount of sodium intake owing to its unique characteristics of the research method and in the processing of data. Although measuring the amount of sodium excreted in 24-hour urine is known to be the most accurate method, because collecting 24-hour urine from the general population is difficult, using spot urine samples to estimate sodium intake has been suggested to be useful for examining the trend of sodium intake in the general population. Therefore, we planned to conduct a study for estimating of 24-hour sodium excretion from spot urine and 8-hour overnight urine samples and testing the validity among subsamples in the KNHANES. Based on this result, we will adopt the most appropriate urine collection method for estimating population sodium intake in South Korea.
\end{abstract}

KEY WORDS: Sodium, Urine, Nutrition assessment, Dietary Reference Intake, Validity, Korea National Health and Nutrition Examination Survey

\section{INTRODUCTION}

Excessive sodium intake is a risk factor for hypertension, cardiovascular diseases, kidney diseases, and gastric cancer, and indirectly functions as a factor that can increase the risks of obesity, kidney stones, and osteoporosis. Reducing sodium intake

\section{Correspondence: Kyungwon Oh}

Division of Health and Nutrition Survey, Korea Centers for Disease Control and Prevention, 187 Osongsaengmyeong 2-ro, Cheongju 363-951, Korea Tel: +82-43-719-7460, Fax: +82-43-719-7527, E-mail: kwoh27@korea.kr

Received: Oct 13, 2014, Accepted: Nov 28, 2014, Published: Nov 28, 2014

This article is available from: http://e-epih.org/

(C) 2014, Korean Society of Epidemiology

(C) This is an open-access article distributed under the terms of the Creative Commons Attribution License (http://creativecommons.org/licenses/by/3.0/), which permits unrestricted use, distribution, and reproduction in any medium, provided the original work is properly cited. significantly decreases the prevalence and mortality rates of chronic diseases [1]. It is well known that Korean consume too much sodium from traditional foods, such as kimchi, soy sauce and paste, salt-fermented seafood, soups, and stews; hence, policy-based approaches that can reduce sodium intake are urgently needed. Furthermore, in order to establish reduction goals and evaluate the effectiveness of sodium reduction programs, it is essential to accurately estimate sodium intake and continue to monitor trend in sodium intake in South Korea. Sodium intake can be investigated with nutrition surveys using 24-hour dietary recall or food records, as well as through amount of sodium excreted in 24-hour urine, 8-12 overnight urine, and spot urine samples; moreover, the methods for estimating sodium intake vary for each country, with each having its own advantages and disadvantages [2].

The aims of this study were to identify the status of sodium in- 
take in South Korea and to review the methods for estimating sodium intake for each country and their validity; through this, we will establish a method for accurately estimating and monitoring sodium intake in a representative Korean population.

\section{STATUS OF SODIUM INTAKE IN SOUTH KOREA}

According to the 2012 Korea National Health and Nutrition Examination Survey (KNHANES) [3], the daily sodium intake for Koreans was 4,546 mg (men, 5,212 mg; women, 3,868 mg), which exceeded 2-fold of the recommended maximum daily intake of 2,000 mg [4], established by the World Health Organization (WHO) (Figure 1). In looking at the trend in sodium intake (over 1 years old, age-standardized) since 1998, when KNHANES was first conducted, mean daily intake of sodium increased from 4,582 mg in 1998 to 5,260 mg in 2005; however, sodium intake decreased to $4,453 \mathrm{mg}$ in 2007 , when the revised food composition table was established. On the basis of the trends since 2007, wherein the same food composition table was applied, sodium intake showed slight increases at 4,608, 4,618, and 4,785 $\mathrm{mg}$ in 2008, 2009, and 2010, respectively, but

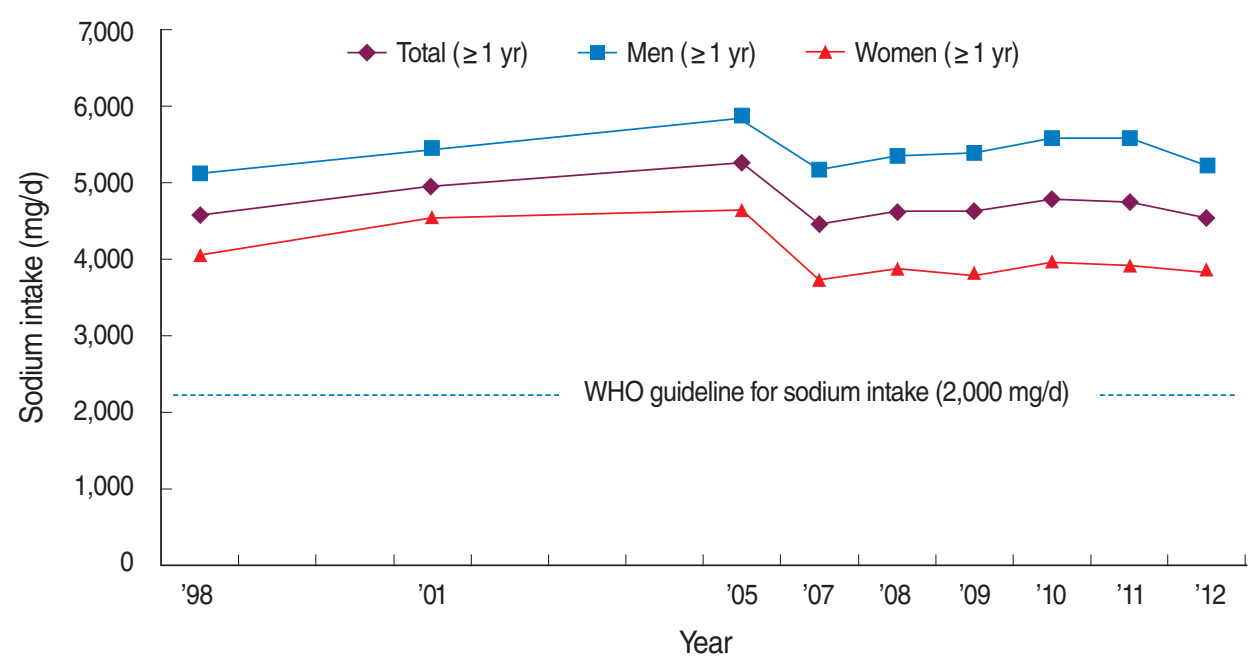

Figure 1. Trend in mean daily intake of sodium among Koreans above 1 year of age, Korea National Health and Nutrition Examination Survey (1998-2012). The age-standardized mean was calculated using an estimated population, based on the 2005 census of the Korean population. Since 2007, a revised food composition table was used to calculate the sodium intake.

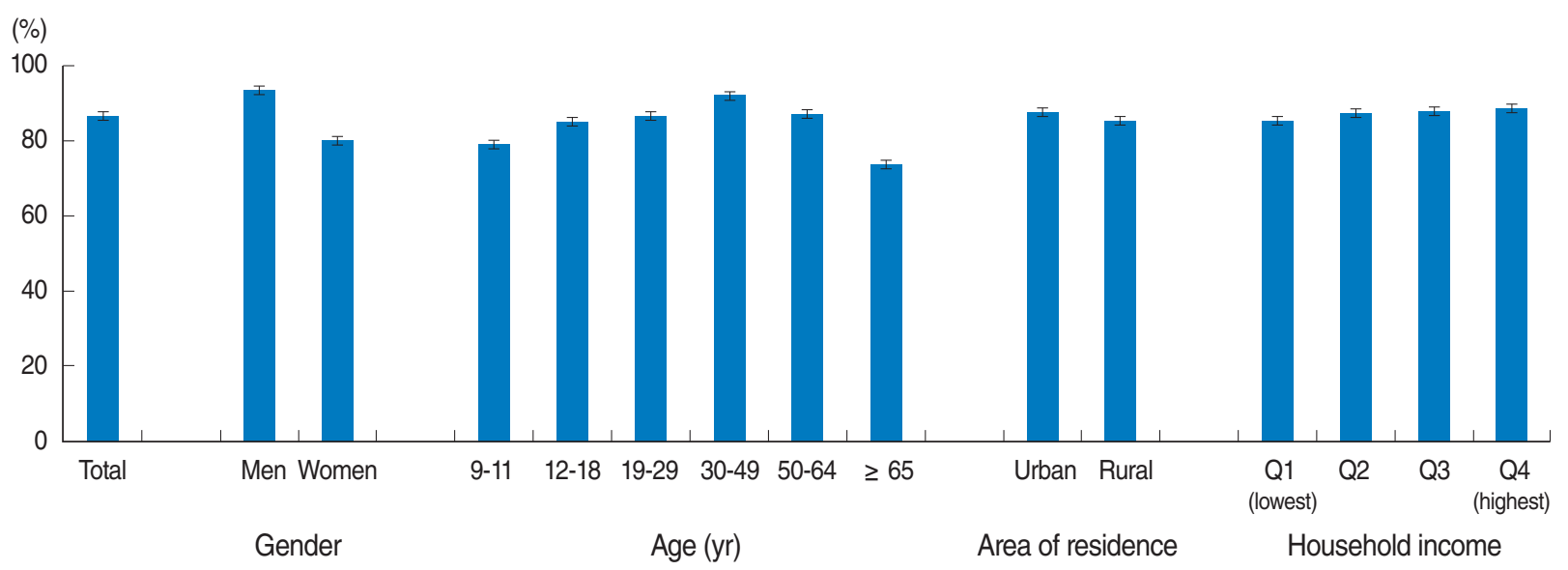

Figure 2. Prevalence of excessive sodium intake compared to the Korean Dietary Reference Intake among Koreans above 9 years of age, the 2012 Korea National Health and Nutrition Examination Survey. Values are presented as percentages and confidence intervals. The goal for sodium intake of Korean Dietary Reference Intake was established at 2,000 mg/d for those above 9 years of age. The age-standardized prevalence according to the area of residence and household income was calculated using an estimated population, based on the 2005 census of the Korean population. 
it continuously decreased thereafter to $4,752 \mathrm{mg}$ in 2011 and $4,546 \mathrm{mg}$ in 2012 . The daily sodium intake in men was higher than that in women by approximately 1,000-1,500 $\mathrm{mg}$, which was attributable to higher consumption of food in men compared to women; however, annual trends for both men and women showed similar patterns.

In the 2012 KNHANES, the percentage of excessive sodium intake compared to the goal for sodium intake (9 years or older, 2,000 mg) established by the Korean Dietary Reference Intake was $93.3 \%$ for men and $79.8 \%$ for women aged 9 years or older (Figure 2); moreover, the percentage of excessive sodium intake in people in their 30s and 40s appeared to be the highest at $91.9 \%$ (men, 96.9\%; women, $86.7 \%$ ). Regardless of area of residence or household income level, over $85 \%$ of the subjects showed excessive sodium intake.

\section{ADVANTAGES, DISADVANTAGES, ANDVALIDITY OF METHODS FOR ESTIMATING SODIUM INTAKE}

Daily sodium intake can be measured with the nutrition survey methods, such as 24-hour dietary recall and food records, and through amount of sodium excreted in 24-hour urine, 8-12 overnight urine, and spot urine samples.

Among these methods, the 24-hour urinary sodium excretion is known to be the gold standard method for measuring sodium intake, because $85-95 \%$ of consumed sodium is excreted through urine and sodium in urine is highly correlated with sodium intake from food [5]. Nevertheless, the 24-hour urine collection has the disadvantages that urine collection without loss for 24hour from the general population that engages in free lifestyle is difficult and imposes a high burden on the participants [2]. In the National Diet and Nutrition Survey (England), the North Karelia Salt Project (Finland), FINMONICA Study (Finland), and the national FINRISK Study (Finland), 24-hour urine from a representative sample has been continuously collected to monitor the average sodium intake of their citizens.

A nutrition survey using 24-hour dietary recall or food records can be a relatively useful method in a large-scale population study, but it is subject to several limitations [6]; there are difficulties in recalling exactly how much of what type food was consumed for the past 1 day, as well as determining exactly how much salt was added during cooking. In addition, by applying the same value of sodium in dish to all, it has the disadvantage of not being able to reflect individual differences in salt intake. Moreover, since the food composition table is amended every 5 years, it presents limitations in making comparisons in annual trends. Sodium intake has been estimated from a 24hour dietary recall for 1-day in KNHANES, 24-hour dietary recall for 1-2 days in the National Health and Nutrition Examination Survey in the US, and a semi-weighted food record method for 1 day (3 days before 1995) in the Japanese National Nutrition Survey. The validity of 24-hour dietary recall methods for estimating sodium intake varies for each country, based on primary food consumed and cooking characteristics (Table 1) [7-11]. In the West, the primary source of sodium intake is processed foods (US, 77\% [12]; UK, 65-70\% [13]), which allows determination of a significant portion of individual sodium intake from food intake alone; thus, the correlation coefficients with 24-hour urinary sodium excretion were approximately $0.3-0.4[7,9,11]$. However, in a study on Koreans, the results indicated that the correlation coefficient between the sodium intake from 24-hour dietary recall and 24-hour urinary sodium excretion was 0.11 [10]. One of the reasons for such a low correlation is considered to be difficulties associated with the fact that the primary sources of sodium intake for Koreans are cooked dishes, such as kimchi, soups, and stews; the amount of ingredients and the amount of seasonings added could not be identified in the cooked foods, despite the fact that there can be significant differences among individuals based on sensitivity to

Table 1. Studies that compared the 24-hour dietary recall method with the 24-hour urine collection method for the estimation of sodium intake in a healthy population

\begin{tabular}{|c|c|c|c|c|c|c|}
\hline $\begin{array}{l}\text { Authors (published year) } \\
\text { [Ref] }\end{array}$ & Country & Population & Sample size (age) & $\begin{array}{l}\text { No. of days } \\
\text { of } 24 \text {-hour } \\
\text { recall }\end{array}$ & $\begin{array}{l}\text { No. of days } \\
\text { of } 24 \text {-hour } \\
\text { urine }\end{array}$ & $\begin{array}{c}\text { Correlation coefficient between } \\
\text { dietary sodium intake and } 24 \text {-hour } \\
\text { urinary sodium }\end{array}$ \\
\hline Espeland et al. (2001) [7] & US & $\begin{array}{r}\text { Elderly cohort } \\
\text { participants }\end{array}$ & $\begin{array}{l}\text { M: } 181, \mathrm{~F}: 160 \\
(60-79 \mathrm{yr})\end{array}$ & 5 & 5 & $r=0.30$ \\
\hline Sasaki et al. (2003) [8] & Japan & Cohort participants & M: 32, F: 57 & 28 & 2 & $\begin{array}{l}r=0.38 \text { for men } \\
r=0.47 \text { for women }\end{array}$ \\
\hline Reinivuo et al. (2006) [9] & Finland & Random population & $\begin{array}{l}\text { M: 410, F: } 469 \\
(25-64 \mathrm{yr})\end{array}$ & 2 & 1 & $r=0.3$ \\
\hline Shin et al. (2010) [10] & South Korea & Healthy volunteers & F: 236 ( $\geq 20 y r)$ & 3 & 1 & $r=0.11$ \\
\hline Rhodes et al. (2013) [11] & US & Healthy volunteers & $\begin{array}{c}\text { M: 232, F: } 233 \\
(30-69 \mathrm{yr})\end{array}$ & $1-2$ & $1-2$ & $\begin{array}{l}r=0.18-0.43 \text { according to the } \\
\text { body mass index }\end{array}$ \\
\hline
\end{tabular}

Ref, reference; M, male; F, female. 
Table 2. Studies that compared spot or overnight urine samples with the 24-hour urine samples for the estimation of sodium intake in a healthy population

\begin{tabular}{|c|c|c|c|c|c|}
\hline Authors (published year) [Ref] & Country & Population & Sample size (age) & Type of urine sample & $\begin{array}{l}\text { Correlation coefficient between } \\
\text { spot or overnight urinary sodium } \\
\text { and 24-hour urinary sodium }\end{array}$ \\
\hline \multicolumn{6}{|l|}{ Spot urine samples } \\
\hline Kawasaki et al. (1982) [15] & Japan & Healthy volunteers & $\begin{array}{l}\text { M: 91, F: } 151 \\
\text { (20-63 yr) }\end{array}$ & Spot urine & $\begin{aligned} r= & 0.47 \text { for } 1 \mathrm{~d} \\
r= & 0.73 \text { for } 1 \mathrm{~d} \text { after discarding } \\
& \text { outliers } \\
r= & 0.62 \text { for } 3 \mathrm{~d}\end{aligned}$ \\
\hline Kawasaki et al. (1993) [16] & Japan & $\begin{array}{l}\text { Healthy free-living } \\
\text { individuals }\end{array}$ & Adults: 159 (20-79 yr) & $\begin{array}{l}\text { Spot urine (second } \\
\text { morning urine) }\end{array}$ & $\begin{array}{l}r=0.728 \\
r=0.51 \text { for } 1 d \text { to } 0.82 \text { for } 3 d\end{array}$ \\
\hline Costa et al. (1994) [17] & Brazil & Healthy individuals & Adults: 611 (20-74 yr) & Spot urine & $r=0.28$ \\
\hline Tanaka et al. (2002) [14] & Japan & INTERSALT participants & $\begin{array}{l}\text { M: 295, F: } 296 \\
(20-59 \mathrm{yr})\end{array}$ & Spot urine & $r=0.54$ \\
\hline Mann \& Gerber (2010) [18] & US & Unselected volunteers & M: 81 (21-82 yr) & $\begin{array}{l}\text { Spot urine } \\
\text { Morning urine } \\
\text { Evening urine }\end{array}$ & $\begin{array}{l}r=0.17 \\
r=0.31 \\
r=0.86\end{array}$ \\
\hline Brown et al. (2013) [19] & Europe & $\begin{array}{l}\text { INTERSALT participants } \\
\text { (29 populations) }\end{array}$ & $\begin{array}{l}\text { M: 1,369, F: 1,376 } \\
(20-59 \mathrm{yr})\end{array}$ & $\begin{array}{l}\text { Spot urine (individual level) } \\
\text { Spot urine (population level) }\end{array}$ & $\begin{array}{l}r=0.50 \text { for men } \\
r=0.51 \text { for women } \\
r=0.79 \text { for men } \\
r=0.71 \text { for women }\end{array}$ \\
\hline \multicolumn{6}{|l|}{ Overnight urine samples } \\
\hline Watson \& Langford (1970) [20] & US & Students & F: 52 (20-22 yr) & Overnight urine & $r=0.76$ \\
\hline Liu et al. (1979) [21] & US & Volunteers & M: 116 (30-44 yr) & Overnight urine & $r=0.72$ \\
\hline $\begin{array}{l}\text { Kamata \& Tochikubo } \\
\text { (2002) [22] }\end{array}$ & Japan & Healthy individuals & $\begin{array}{l}\text { M: } 71 . F: 78 \\
(35-49 \mathrm{yr})\end{array}$ & Overnight urine & $\begin{array}{l}r=0.73 \text { for men } \\
r=0.78 \text { for women }\end{array}$ \\
\hline
\end{tabular}

Ref, reference; M, male; F, female.

salt and the amount of salt added during cooking. It makes difficult to estimate individuals' sodium intake with the application of a standardized amount of ingredients in cooked dishes.

The use of sodium concentration in spot urine as a method for estimating daily sodium intake has the advantage of placing fewer burdens on participants, but it is limited in accurately measuring an individual's sodium intake due to the fact that sodium concentration can easily be affected by the volume of fluid ingested [2]. Despite this disadvantage, spot urine has been considered a useful method for estimating population mean value of sodium intake. It makes it possible to compare the sodium intake between different population and monitor trends over time within a specific population [14]. The correlation coefficients between sodium concentration in spot urine and sodium concentration in 24-hour urine were 0.28-0.86 [14-19], with differences observed in the time and frequency of spot urine collection (Table 2). An 8-12 hour overnight urine method has the advantage of low-burden urine collection than 24hour urine method, but it has the disadvantages of needing to collect the urine under strict time constraints and requires the assumption that urine excretion is constant day and night despite of usual diurnal pattern in excretion of sodium (i.e., higher excretion during the day). In the case of overnight urine, its correlation coefficients with 24-hour urine were 0.59-0.78 [20-
22], which indicates that it is more valid as a substitute for 24hour urine than spot urine (Table 2).

\section{IMPROVEMENT OF METHODS FOR ESTIMATING SODIUM INTAKE IN KOREA NATIONAL HEALTHAND NUTRITION EXAMINATION SURVEY}

Although a 24-hour dietary recall method has been used to estimate the average sodium intake of Koreans in KNHANES, as previously mentioned, a 24-hour dietary recall method has limitation in making accurate measures of sodium intake owing to its unique characteristics as a research method and in the processing of data. As such, in order to improve upon the limitations of the nutrition survey, we planned to adopt methods for estimating sodium intake using urine in KNHANES; however, prior to this introduction, an examination of the feasibility and validity of various urine sodium measurement methods is required. Accordingly, a study on the estimation methods for sodium intake in KNHANES is currently underway as a research project of the Korea Centers for Disease Control and Prevention, and 24-hour urine, 8-hour overnight urine, and spot urine samples from 300 adults who had participated in KNHANES is collecting to develop a formula for estimating 
sodium intake for Korean, and to test the validity of the sodium intake estimation method using spot urine and 8-hour overnight urine samples through comparisons with 24-hour urinary sodium excretion. Through the present study, guidelines for the most appropriate urine collection method, collection time, and collection amount for estimating sodium intake of Koreans will be developed and adopted in KNHANES. It is anticipated that the sodium intake estimated with spot urine or 8-hour overnight urine samples will complement the results of the 24-hour dietary recall method used in KNHANES; moreover, the sodium intake by Koreans estimated through this method is expected to be used as the basis for promoting policies on sodium reduction, developing health policies, and evaluating their effectiveness.

\section{ACKNOWLEDGEMENTS}

The KNHANES has been financially supported by the Health Promotion Fund with administrative support by the Ministry of Health and Welfare.

\section{CONFLICT OF INTEREST}

The authors have no conflicts of interest to declare for this study.

\section{SUPPLEMENTARY MATERIAL}

Supplementary material is available at http://www.e-epih.org/.

\section{REFERENCES}

1. He FJ, MacGregor GA. Reducing population salt intake worldwide: from evidence to implementation. Prog Cardiovasc Dis 2010;52:363382.

2. Elliott P, Brown I. Sodium intakes around the world. Geneva: World Health Organization; 2007, p. 6-15.

3. Korea Centers for Disease Control and Prevention. Korea health statistics 2012: Korea National Health and Nutritional Examination Survey (KNHANES V-3). Cheongju: Korea Centers for Disease Control and Prevention; 2013, p. 390-399, 520-524.

4. World Health Organization. Diet, nutrition, and the prevention of chronic diseases: report of a joint WHO/FAO expert consultation. Geneva: World Health Organization; 2003, p. 56.

5. Kirkendall AM, Connor WE, Abboud F, Rastogi SP, Anderson TA, Fry M. The effect of dietary sodium chloride on blood pressure, body fluids, electrolytes, renal function, and serum lipids of normotensive man. J Lab Clin Med 1976;87:411-434.

6. World Health Organization. Strategies to monitor and evaluate population sodium consumption and sources of sodium in the diet. Geneva: World Health Organizatio; 2011, p. 6-12.

7. Espeland MA, Kumanyika S, Wilson AC, Reboussin DM, Easter L, Self M, et al. Statistical issues in analyzing 24-hour dietary recall and 24-hour urine collection data for sodium and potassium intakes. Am J Epidemiol 2001;153:996-1006.

8. Sasaki S, Ishihara J, Tsugane S; JPHC. Validity of a self-administered food frequency questionnaire in the 5-year follow-up survey of the JPHC Study Cohort I to assess sodium and potassium intake: comparison with dietary records and 24-hour urinary excretion level. J Epidemiol. 2003;13:S102-S105.

9. Reinivuo H, Valsta LM, Laatikainen T, Tuomilehto J, Pietinen P. Sodium in the Finnish diet: II trends in dietary sodium intake and comparison between intake and 24-h excretion of sodium. Eur J Clin Nutr 2006;60:1160-1167.

10. Shin EK, Lee HJ, Lee JJ, Ann MY, Son SM, Lee YK. Estimation of sodium intake of adult female by 24-hour urine analysis, dietary records and dish frequency questionnaire (DFQ 55). Korean J Nutr 2010; 43:79-85.

11. Rhodes DG, Murayi T, Clemens JC, Baer DJ, Sebastian RS, Moshfegh AJ. The USDA Automated Multiple-Pass Method accurately assesses population sodium intakes. Am J Clin Nutr 2013;97:958964.

12. Mattes RD, Donnelly D. Relative contributions of dietary sodium sources. J Am Coll Nutr 1991;10:383-393.

13. Bull NL, Buss DH. Contributions of foods to sodium intakes. Proc Nutr Soc 1980;39:30A.

14. Tanaka T, Okamura T, Miura K, Kadowaki T, Ueshima H, Nakagawa $\mathrm{H}$, et al. A simple method to estimate populational 24-h urinary sodium and potassium excretion using a casual urine specimen. $\mathrm{J}$ Hum Hypertens 2002;16:97-103.

15. Kawasaki T, Ueno M, Uezono K, Kawazoe N, Nakamuta S, Ueda K, et al. Average urinary excretion of sodium in 24 hours can be estimated from a spot-urine specimen. Jpn Circ J 1982;46:948-953.

16. Kawasaki T, Itoh K, Uezono K, Sasaki H. A simple method for estimating $24 \mathrm{~h}$ urinary sodium and potassium excretion from second morning voiding urine specimen in adults. Clin Exp Pharmacol Physiol 1993;20:7-14.

17. Costa Ede A, Rose G, Klein CH, Achutti AC. Diastolic pressure as an index of salt sensitivity. J Hum Hypertens 1994;8:703-709.

18. Mann SJ, Gerber LM. Estimation of 24-hour sodium excretion from spot urine samples. J Clin Hypertens (Greenwich) 2010;12:174-180

19. Brown IJ, Dyer AR, Chan Q, Cogswell ME, Ueshima H, Stamler J, et al. Estimating 24-hour urinary sodium excretion from casual urinary sodium concentrations in Western populations: the INTERSALT study. Am J Epidemiol 2013;177:1180-1192.

20. Watson RL, Langford HG. Usefulness of overnight urines in population groups. Pilot studies of sodium, potassium, and calcium excretion. Am J Clin Nutr 1970;23:290-304.

21. Liu K, Dyer AR, Cooper RS, Stamler R, Stamler J. Can overnight urine replace 24-hour urine collection to asses salt intake? Hypertension 1979;1:529-536.

22. Kamata K, Tochikubo O. Estimation of 24-h urinary sodium excretion using lean body mass and overnight urine collected by a pipesampling method. J Hypertens 2002;20:2191-2197. 